\title{
Self-Expanding Metal Stents for Palliative Treatment of Superior Vena Caval Syndrome
}

\author{
Matthijs Oudkerk, ${ }^{1}$ Theodore J.A. Kuijpers, ${ }^{1}$ Paul I.M. Schmitz, ${ }^{2}$ Olaf Loosveld, ${ }^{3}$ Ronald de Wit ${ }^{3}$ \\ ${ }^{1}$ Department of Radiodiagnostics, Dr. Daniel den Hoed Cancer Center/University Hospital Rotterdam, Groene Hilledijk 301, NL-3075 EA \\ Rotterdam, The Netherlands \\ ${ }^{2}$ Department of Statistics, Dr. Daniel den Hoed Cancer Center/University Hospital Rotterdam, Groene Hilledijk 301, NL-3075 EA \\ Rotterdam, The Netherlands \\ ${ }^{3}$ Department of Medical Oncology, Dr. Daniel den Hoed Cancer Center/University Hospital Rotterdam, Groene Hilledijk 301, NL-3075 EA \\ Rotterdam, The Netherlands
}

\begin{abstract}
Purpose: Two stent types (a new Wallstent and a Zstent) were investigated in 30 patients with recurrent malignant superior vena caval syndrome (SVCS).

Methods: Eligibility requirements were that the patient had recurrent symptoms after appropriate radiation therapy, chemotherapy, or both; $\geq 75 \%$ of the vessel was occluded; and there was collateral flow. Because of the limited availability of stents, it was not possible to perform a prospectively randomized study.

Results: In the Z-stent group (17 patients), occlusion of the stent due to acute thrombosis occurred within $12 \mathrm{hr}$ in 4 patients (24\%), but in the other 13 patients (76\%) symptoms disappeared completely. After 2 weeks the cavogram in these patients showed no signs of thrombosis, and $12(71 \%)$ of the patients remained symptomfree. There was partial occlusion in 5 patients $(29 \%)$, without relevant clinical symptoms. Of the 13 patients who received Wallstents, only 1 had an acute immediate thrombosis $(8 \%)$. Symptoms disappeared completely in the other 12 patients and no signs of thrombosis were seen. However, after 2 weeks complete stent occlusion with SVCS was found in 3 patients (23\%) and partial occlusion with minor clinical symptoms in $6(46 \%)$. Only 3 patients (23\%) had complete relief of their SVCS. The difference between the rates of occlusion of the two stents after 2 weeks was highly significant $(p=0.008)$.

Conclusions: The overall clinical success rate for longterm patency was $100 \%$ for the Z-stents and $69 \%$ for the new Wallstent. These results suggest that when
\end{abstract}

Correspondence to: M. Oudkerk, M.D., Ph.D. used for this purpose, the new Wallstent is more thrombogenic at 2 weeks than the Z-stent.

Key words: Superior vena caval syndrome-Wallstent vs. Z-stent-Palliative treatment

Superior vena caval syndrome (SVCS) secondary to malignant disease is traditionally treated by radiation therapy, chemotherapy, or both. Initial success rates have been reported to exceed $90 \%$. Recurrence of SVCS, however, develops in $10 \%-20 \%$ of patients [1, 2]. It may be caused by tumor recurrence, postradiation fibrosis, or superimposed thrombosis. Patients treated with radiation therapy are usually given a maximumtolerance dose, so treatment of recurrence is difficult or impossible. Intraluminal stenting can provide sufficient force to reopen the vessel lumen and prevent tumor and thrombotic occlusion.

Since 1986 more than 100 palliative SVCS stent procedures have been reported in the literature [2-8]. In our initial series of 22 patients [9] with malignant caval obstruction, palliative stenting was performed mainly with Z-stents. The complication rate directly related to the superior vena cava (SVC) was $18 \%$. Stent occlusion due to thrombosis, tumor encasement, or both, was the major complication in this group of patients. A new Wallstent - adapted to the dimensions of the SVC - might prohibit such occlusion by its closer wire structure, which prevents tumor ingrowth through the struts.

The purpose of this study was to compare the results of these two stents in SVCS patients. Because of the limited availability of the new Wallstent, it was not 


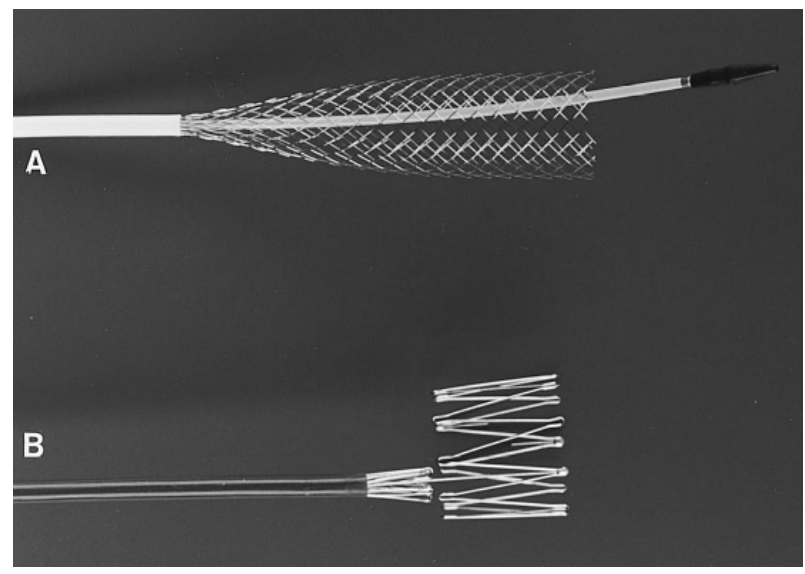

Fig. 1. A New, longer Wallstent partially released from the delivery device (diameter $11.5 \mathrm{Fr}$, length $112 \mathrm{~cm}$, guidewire $0.38 \mathrm{inch}$ ). B Double Gianturco Z-stent partially released from the delivery device (diameter 11.0 Fr, length $60 \mathrm{~cm}$, guidewire $0.38 \mathrm{inch}$ ). Note the unfolded second part of the double Z-stent.
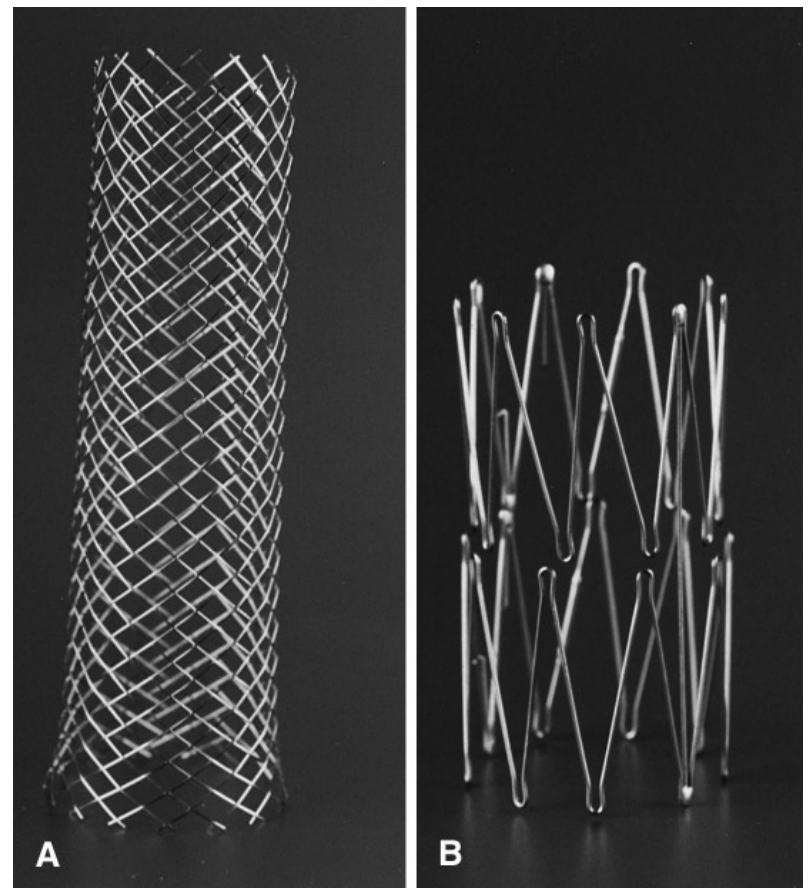

Fig. 2. A Unfolded longer Wallstent (diameter $20 \mathrm{~mm}$, length 70 $\mathrm{mm}$ ). B Unfolded Gianturco double Z-stent (diameter $20 \mathrm{~mm}$, length $50 \mathrm{~mm}$ ). Note that the magnification factor of the two stents is not the same.

possible to conduct a randomized study. A series of 30 patients who had recurrent malignant SVC obstruction after appropriate radiotherapy, chemotherapy, or both and in whom palliative stenting was performed with either the new Wallstent or a Z-stent are reported.
Table 1. Patient characteristics

\begin{tabular}{lll}
\hline Characteristic & Wallstent & Z-stent \\
\hline No. of patients & 13 & 17 \\
Sex (M/F) & $10 / 3$ & $11 / 6$ \\
Age (years) & \\
Tumor type & $61(40-74)$ & $60(45-74)$ \\
$\quad$ Lung & 9 & \\
$\quad$ Other & 4 & 11 \\
Previous radiotherapy & & 6 \\
$\quad$ No. of patients & 11 & 11 \\
$\quad$ Dose (Gy) & $40(20-66)$ & $45(20-60)$ \\
Previous chemotherapy & 4 & 8 \\
\hline
\end{tabular}

${ }^{a}$ Values are the median (range)

\section{Methods}

Patients were accepted for the stent procedure if there was clinical evidence of recurrent SVCS proved by cavography. All patients had recurrent symptoms after appropriate external beam radiation therapy, chemotherapy, or both but were not amenable to further therapy. Patients were required to have a $\geq 75 \%$ vessel occlusion (diameter) and collateral flow. The following contraindications for the stent procedure were applied: (1) chronic complete vessel occlusion proved by computed tomography (CT) or angiography; (2) severe coagulopathy; (3) congestive or ischemic heart disease requiring medication; (4) impossibility of passing or dilating a high-grade or complete SVC obstruction.

For the initial diagnostic cavography an 18-gauge Venflon sheath was placed in the cubital veins of both arms, and $80 \mathrm{ml}$ of iopromide $(300 \mathrm{mg} \mathrm{I} / \mathrm{ml}$ ) injected at a flow rate of $20 \mathrm{ml} / \mathrm{sec}$ simultaneously on the two sides $(40 \mathrm{ml}$ each side). If necessary an ultrasound-guided procedure was performed to place the Venflon sheath in the vessel. A digital subtraction series of the thorax aperture and mediastinum was obtained during injection (Digitron 3, Siemens, Erlangen, Germany) using three images per second.

During the diagnostic procedure the optimal approach for passing and stenting the SVC was explored. Full-dose heparin $(25,000 \mathrm{U} /$ day) was instituted before the stent procedure and continued for a maximum of 2 weeks after stenting with prolongation of the partial thromboplastin time (PTT) 2.5-fold, starting 1 day prior to stent placement. Thereafter, patients received lifetime coumarin anticoagulant therapy. The stent procedure was performed via the femoral approach, and immediately before placing the stent a transcatheter injection of streptokinase 50,000 U was administered locally. After the procedure streptokinase $10,000 \mathrm{U} / \mathrm{hr}$ was administered through the catheter for $12 \mathrm{hr}$. Stent procedures were undertaken with continuous electrocardiographic monitoring in all patients. Follow-up cavography was performed in all patients before they were discharged from the hospital 2 weeks after the operation. This was performed in the same manner as the initial diagnostic cavography.

The stent introducer diameter varied from $10 \mathrm{Fr}$ for Z-stents to $12 \mathrm{Fr}$ for the Wallstents; balloon dilatation up to $20 \mathrm{~mm}$ was performed only before stent placement. In all patients stents were placed with a guidewire passing the stenosis. The appropriate stent length was determined during the procedure according to the results of the diagnostic radiologic series or the balloon dilatation during the interventional session. A follow-up cavogram was performed 2 weeks after stent placement and a longer follow-up was achieved clinically.

Because the new Wallstent was custom-made and not always available, the study design was not randomized. Whenever both stents were available, patients were allocated statistically to either the Wallstent or the Z-stent group before diagnostic cavography was performed. This assignment appeared to be random, as tested with the one sample runs test $(p>0.05)$. All patients gave informed consent.

The new Wallstent that was used has the advantage of undergoing less shortening, compared with former stent designs, after release 


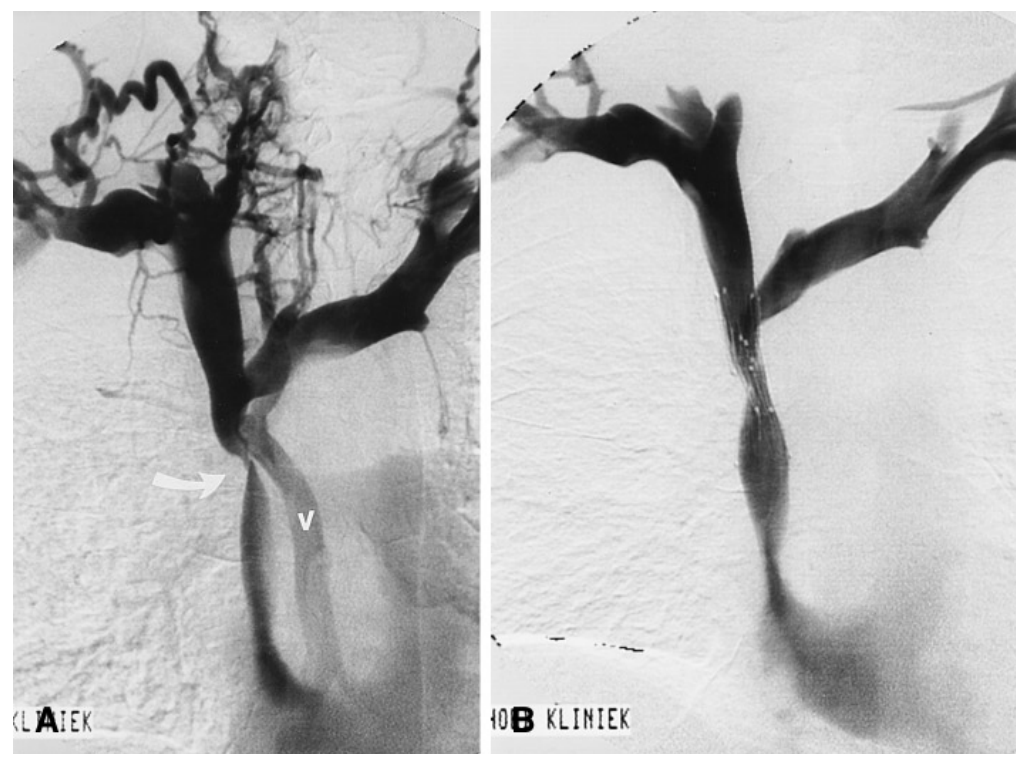

Fig. 3. A Cavography. Subtotal stenosis is seen at the entry of the superior vena cava (SVC) (arrow). Collateral flow is seen at the thorax aperture and retrograde flow in the azygos vein (v). B Cavography 1 week after stent placement of one double and one single Z-stent. Unimpaired flow through the SVC to the right atrium is demonstrated without collateral flow or retrograde flow in the azygos vein. from the catheter (Fig. 1A). The wire has a more rigid structure, with a maximum diameter of $20 \mathrm{~mm}$ and a length (fully open) of $70 \mathrm{~mm}$ (Fig. 2A). The constrained length of the stent is $10 \mathrm{~cm}$, fixed on a 90-cm introducer. The new Wallstent (Schneider Europe, Bülach, Switzerland) is a noncoated version of the esophageal Wallstent. Single and double Z-stents (William Cook Europe, Bjaeverskor, Denmark) were used in the other patients (Fig. 1B). The expandable metallic Z-stents are constructed of a stainless-steel wire bent in a zigzag pattern to form a cylinder. This stent is compressed and introduced through a Teflon catheter (length $60-90 \mathrm{~cm}$, diameter $10 \mathrm{Fr}$ ) depending on the caliber of the wire and the diameter of the stent. When the stent is released from the catheter, it expands to its original diameter. The fully expanded stent diameter is $20 \mathrm{~mm}$, and the stent length varies from $20 \mathrm{~mm}$ (single), to $50 \mathrm{~mm}$ (double) (Fig. 2B), to $70 \mathrm{~mm}$ (double plus single). The mean length of vessel occlusion in the patients who received Wallstents was $6.23 \mathrm{~cm}$, with the stented segment varying from 7 to $8 \mathrm{~cm}$. The mean length of vessel occlusion in patients who received Z-stents was $5.13 \mathrm{~cm}$, with a mean stented segment of $6.1 \mathrm{~cm}$.

In the statistical analysis the percentage of successful results was determined on the day of the procedure and at 2 weeks. These data were compared using Fisher's exact test for a $2 \times 2$ or a $3 \times 2$ table (significance level 5\%). Survival times were compared with the logrank test.

\section{Results}

During a 36-month period, 54 patients with cancer were referred for a stenting procedure of the SVC. Thirty of them had a vessel occlusion of $75 \%-100 \%$ and had developed collateral flow, making them eligible to undergo the procedure. Twenty-four patients were excluded due to contraindications, mainly chronic complete obstruction (14 patients). The 30 eligible patients had had a relapse of SVCS caused by recurrent malignant disease, and all had previously been treated with chemotherapy, radiation therapy, or both. Patient characteristics are shown in Table 1.
Z-stents were placed in 17 patients; 94\% (16 of 17) of the stents were of the double Z-type. One patient received a double plus single Z-stent (Fig. 3). The new Wallstents were placed in 13 patients (Figs. 4, 5; Table 2). Most stents were opened to a maximum diameter of $10-20 \mathrm{~mm}$. In 2 patients the maximum expanded diameter was less than $10 \mathrm{~mm}$ (one Z-stent, one Wallstent). The stents were positioned correctly in all patients. The mean prestent lumen was $9 \%$ in the Z-stent patients, and the mean poststent lumen improved to $59 \%$ of the original lumen diameter. The mean prestent lumen was $8 \%$ in the Wallstent patients, and their mean poststent lumen improved to $66 \%$ of the original lumen diameter. Despite heparin and streptokinase prophylaxis, stent occlusion due to acute thrombosis occurred within $12 \mathrm{hr}$ in 4 of the 17 patients who were given a Z-stent (24\%). The SVC was opened successfully in all of these 4 patients with a repeated bolus injection of $50,000 \mathrm{U}$ of streptokinase (to a maximum of 150,000 $\mathrm{U})$ through the catheter, with the tip in the thrombus. After 2 weeks, all 17 Z-stents were open with complete relief of symptoms.

Among the 13 patients who received Wallstents, complete relief of symptoms was achieved in $12(92 \%)$ and no signs of thrombosis were seen. One patient had acute stent occlusion and died from massive hemoptysis during thrombolytic therapy. After 2 weeks, however, recurrence of the clinical syndrome with complete Wallstent occlusion was found in 3 patients (23\%) (Fig. $6 \mathrm{~A}, \mathrm{~B})$, and the lumen failed to reopen permanently even after local streptokinase treatment. Partial occlusion with minor clinical symptoms (e.g., headaches, continuing discomfort in the supine position) was seen in 6 patients (46\%) (Fig. 6C). The patients with partial occlusion required no further treatment because there 

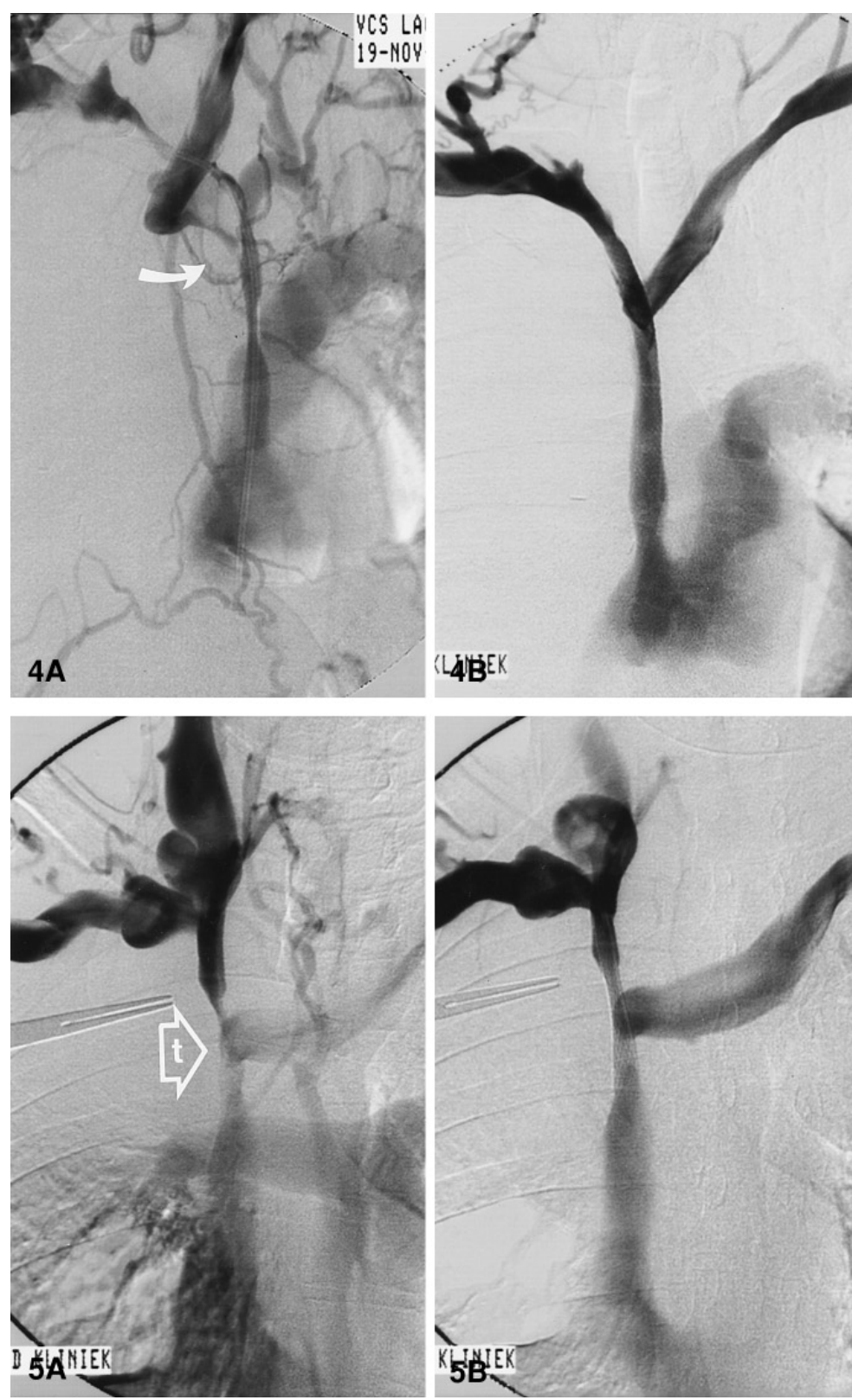

Fig. 4. A Cavography in left oblique projection. A catheter from the right femoral vein passes the stenosis in the SVC, which is subtotally obstructed by tumor compression and thrombosis (arrow). B Cavography in postero-anterior projection 3 months after stent placement of a Wallstent in the SVC. There is complete restoration of flow through the SVC. Note that the structure of the Wallstent is hardly recognizable in the subtraction image.

Fig. 5. A Cavography before stent placement. Subtotal obstruction is seen for more than $5 \mathrm{~cm}$ in the SVC by tumor compression ( $t$ in arrowhead). B Cavography immediately after Wallstent placement shows unimpaired flow through the SVC. Collateral flow is no longer seen. was no recurrence of the full SVCS. Only 3 patients (23\%) did not develop thrombosis during the followup period. No sign of stent migration was noted in this series of patients. Because the disease in these patients was no longer amenable to available treatment, no additional antitumor therapy was given. The mean follow-up period until death was 2.5 months (range $0.5-$ 34 months). No change in clinical status from 2 weeks until death was recorded in either patient group.

The difference between the percentages of stent occlusion on the day of the procedure for the Z-stents and the Wallstents was not statistically significant ( $p=$ 0.36). However, the difference in the distribution of occlusion percentages for the two stent types at 2 weeks was highly significant $(p=0.008)$. Of the 30 patients treated, no patient is still alive; and there was no significant difference in survival between the two study groups $(p=0.82)$.

\section{Discussion}

In this prospective series of 30 patients with recurrent SVCS after radiotherapy, chemotherapy, or both, the overall clinical success rate was $69 \%$ for the new Wallstent and $100 \%$ for the Z-stent. In patients who had 


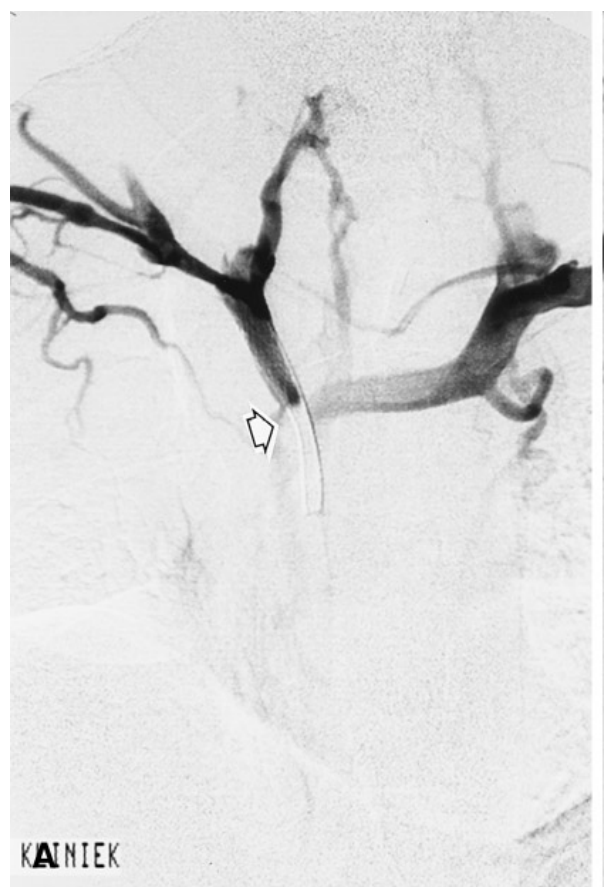

Fig. 6. Three patients with stent thrombosis. A Cavography 3 days after the stent procedure shows complete obstruction of flow in half the lumen of the Wallstent (arrow). B Cavography 3 months after the stent procedure. Complete obstruction of the right anonymous vein is seen at the proximal end of the Wallstent, which has the configu-

received the new Wallstent, the complete occlusion rate at 2 weeks was $23 \%$. Patients with the Z-stent showed complete occlusion earlier, within $12 \mathrm{hr}$ after the procedure $(24 \%)$. The two stent types may thus have about the same rate of thrombotic occlusion but at different points in time, with the new Wallstent developing occlusion later than the $\mathrm{Z}$-stent.

The new Wallstent is longer $(70 \mathrm{~mm})$ than the Z-stent, shows less shortening after placement than the original vascular stent, and has a more compact wire structure. The more rigid structure of this stent could prohibit tumor infiltration. The Z-stent has a more open structure, which allows easy tumor infiltration. Clot formation on the stent wire is a major problem during vascular stent procedures, causing stenosis and occlusion.

Although stent thrombosis is an important issue associated with arterial stenting, prospective clinical data are scarce for venous stenting. Thromboses in venous stents have occasionally been noted in case reports and retrospective data [7-11]. Stent thrombosis of Wallstents has also been mentioned in conjunction with transjugular intrahepatic portosystemic shunt procedures [12], although leakage of bile from the hepatic tract may play a role here. It could be argued that stent occlusion was the result not of stent thrombosis but of tumor growth. The following arguments suggest otherwise. First, one would expect that thrombosis would occur in the stent with the more open structure, which is the Z-stent. This was not the case here. Second, during streptokinase treatment a remarkable improvement of flow through the stent was noted in all control studies. With the Z-stents this reopening could be maintained, but with the Wallstents occlusion recurred after stopping streptokinase treatment in the 3 patients who ultimately developed complete occlusion. Third, it seems unlikely that tumor growth could be responsible for stent occlusion within only a few days. Although the complete occlusion rates between Z-stents and Wallstents are comparable, Z-stents seem to be more easily recanalized than Wallstents, resulting in better overall patency. The acute occlusion in Z-stents is probably due to the damaging force on the vessel wall at the moment of Z-stent unfolding. Moreover, the Z-stent design includes several barbs to prevent stent migration.

The reason for clot formation on the new Wallstents may be related to the relatively small distance between the wires and the impaired flow in the SVC compared with that with the Z-stents. It has been demonstrated that the amount of fibrin-platelet thrombus deposited is proportional to the total metal surface of the stent 
Table 2. Wallstent versus Z-stent for malignant superior vena caval obstruction

\begin{tabular}{lcc}
\hline & $\begin{array}{c}\text { Z-stent } \\
(n=17)\end{array}$ & $\begin{array}{c}\text { Wallstent }^{b} \\
(n=13)\end{array}$ \\
\hline $\begin{array}{l}\text { Day of procedure } \\
\text { Recanalization } \\
\text { Occlusion }\end{array}$ & $13(76 \%)$ & $12(92 \%)$ \\
& $4^{a}(24 \%)$ & $1(8 \%)^{c}$ \\
At 2 weeks after procedure & & $3(23 \%)$ \\
$\quad$ Stent open & $12(71 \%)$ & $6(46 \%)$ \\
$\quad$ Stent partially open & $5(29 \%)$ & $3(23 \%)$ \\
$\quad$ Stent occluded & 0 & \\
\hline
\end{tabular}

${ }^{a}$ All patients received full-dose heparin therapy beginning 1 day before the procedure and continuing for at least 3 days after the procedure. Four patients were successfully treated with selective streptokinase infusion

${ }^{b}$ All patients received full-dose heparin therapy beginning 1 day before the procedure and continuing for at least 3 days after the procedure. Simultaneously, they were given selective streptokinase injection on the day of procedure up to 1 day after the procedure

${ }^{c}$ Patient with acute stent occlusion who died during thrombolytic therapy

[13]. If stents are expanded to a larger diameter, the thrombus spreads over a proportionally larger surface, which reduces the lumen diameter and decreases flow [14]. The fine metal wire structure of the new Wallstent appears to allow less tumor invasion, although the larger total metal surface increases the risk of thrombosis. The Z-stent contains less steel material in relation to the surface area of the vessel. Because the diameter of the Wallstents placed in the SVC did not differ significantly from that of the Z-stent, we believe that the more extensive total metal surface of the new Wallstent, as compared with that of the Z-stent, is involved in the increased thrombogenicity of the Wallstent. Another explanation might be that the Wallstents initially did not open completely. During the expansion that follows over time, the stent places stress on the intimal wall of the vessel, which could damage the vessel wall and cause secondary thrombosis. In 2 patients of this series the stents did not optimally dilate, and the reduced flow precipitated local thrombosis. Both patients showed only partial thrombosis after 2 weeks. Failure of anticoagulant treatment seems unlikely because the anticoagulant therapy in our study was carefully monitored in all patients. According to our data there was no reason to assume that the stent occlusions were due to anticoagulation failures.
Despite the open structure of the Z-stent, which may allow easy tumor ingrowth and infiltration, it is preferred for stent treatment of SVCS because of the smaller number of thrombotic complications. However, except for clinical follow-up, only short-term cavography results are available. It should be noted that a 2week follow-up is not sufficient time to assess how these stents would cope with local tumor ingrowth.

\section{References}

1. Perez CA, Presant CA, Van Amburg AL (1978) Management of superior vena cava syndrome. Semin Oncol 5:123-124

2. Rösch J, Bedell JE, Putnam JS (1987) Gianturco expandable wire stents in the treatment of superior vena cava syndrome recurring after maximum tolerance radiation. Cancer 60:1243-1246

3. Charnsangavej C, Carrasco C, Wallace S, Wright KC, Ogawa K, Richli W, Gianturco C (1986) Stenosis of the vena cava: Preliminary assessment of treatment with expandable metallic stent. Radiology 161:295-298

4. Putnam JS, Uchida BT, Antonovic R, Rösch J (1988) Superior vena cava syndrome associated with massive thrombosis: Treatment with expandable wire stents. Radiology 167:727-728

5. Furui S, Sawada S, Iric T (1990) Hepatic inferior vena cava obstruction: Treatment of two types with Gianturco expandable metallic stents. Radiology 176:665-670

6. Watkinson AF, Hansell DM (1993) Expandable Wallstent for the treatment of obstruction of the superior vena cava. Thorax 48:915-920

7. Dyet JF, Nicholson AA, Cook AM (1993) The use of the Wallstent endovascular prosthesis in the treatment of malignant obstruction of the superior vena cava. Clin Radiol 48:381-385

8. Wright KC, Wallace S, Charnsangavej C, Carrasco HC, Gianturco C (1985) Percutaneous endovascular stents: An experimental evaluation. Radiology 156:69-72

9. Oudkerk M, Heystraten FMJ, Stoter G (1993) Stenting in malignant vena caval obstruction. Cancer 71:142-146

10. Edwards RD, Cassidy J, Taylor A (1992) Case report. Superior vena cava obstruction complicated by central venous thrombosis: Treatment with thrombolysis and Gianturco Z-stents. Clin Radiol 45(4):278-280

11. Rosch J, Uchida BT, Hall LD, Antonovic R, Petersen BD, Ivancev K, Barton RE, Keller FS (1992) Gianturco-Rosch expandable Z-stents in the treatment of superior vena cava syndrome. Cardiovasc Intervent Radiol 15:319-327

12. Hauenstein KH, Haag K, Rössle M, Boos S, Ochs A, Gerok W, Langer M (1994) Palmaz stent versus Wallstent for TIPS: Results of a comparative randomized study in 90 patients. (abstract) Cardiovasc Intervent Radiol 17:S78

13. Palmaz JC, Garcia O, Kopp DT, Schatz RA, Tio FO, Ciaraviro V (1987) Balloon-expandable intraarterial stents: Effect of anticoagulation on thrombus formation. Circulation 76[Suppl 4]:45

14. Sauvage LR (1983) Externally supported, noncrimped externalvelour, weft-knitted Dacron prostheses for axillofemoral, femoropopliteal, and femorotibial bypass. In: Wright CB, Hosson RW, Hiratzka LF, Lynch TB (eds) Vascular Grafting: Clinical Applications and Techniques. Wright, Boston, pp 168-186 